\title{
COMP trace effects across North Germanic varieties ${ }^{1}$
}

\author{
Øystein A. Vangsnes \\ UiT The Arctic University of Norway \\ \& Western Norway University of Applied Sciences
}

\begin{abstract}
Different varieties of North Germanic allow a left peripheral element to immediately precede the trace of an embedded $w h$-subject that has been moved to the matrix left periphery. Across North Germanic we find varieties that allow the insertion of the declarative complementizer at, i.e. similar to English that, but there are also varieties in which we encounter relative markers instead. In varieties of Norwegian the complementizer som may precede the trace of the wh-subject. Faroese is another case, where a group of speakers allows the insertion of the relative marker $i ð$. Danish and Western Jutlandic represent yet another case in that the item der/dce 'there', an element which is otherwise used as a marker of subject relatives as well as functioning as an expletive, also may appear in the corresponding structure.
\end{abstract}

\section{Introduction}

The that trace effect has received considerable attention within generative grammar ever since it was first discussed in Perlmutter $(1968,1971)$ (see Pesetsky, 2016, for a summary). Perlmutter's original observation concerns the ungrammatical status of sentences where the declarative complementizer that is followed by the trace of a moved constituent as in (1b).

\footnotetext{
1 An early version of this paper was presented at GRAMINO 2 in Oslo in May 2018. For very useful comments on a previous version of the paper, I am indebted to Elisabet Engdahl and two anonymous reviewers. Thanks also to Ellen Brandner, Anders Holmberg, and Terje Lohndal for constructive feedback.
}

Ken Ramshøj Christensen, Henrik Jørgensen \& Johanna L. Wood (eds.). 2019.

The Sign of the $V$-Papers in Honour of Sten Vikner. Dept. of English, School of Communication \& Culture, Aarhus University, pp. 657-683, doi:10.7146/aul.348.119. (C) The author(s) 
(1) a. Who do you think that Sue met $t_{i}$ ?

b. $* \mathrm{Who}_{\mathrm{i}}$ do you think that $\mathrm{t}_{\mathrm{i}}$ met Sue?

The existence of the that trace effect in varieties of North Germanic has been demonstrated by many authors, for instance Vikner (1995: 12), who gives the following examples for Danish to show that the declarative complementizer at is not viable in the position preceding the trace of an embedded $w h$-subject that has moved to the left periphery of the matrix clause.

(2)

\section{Danish}

a. Hvem tror du ofte tager til Paris? who think you often goes to Paris

b. *Hvem tror $\mathrm{du}$ at ofte tager til Paris? who think you that often goes to Paris 'Who do you think often goes to Paris?'

Yet, several exceptions to the that trace effect have been reported for various varieties of the Mainland North Germanic languages. Fenno-Swedish and varieties of Eastern Norwegian in particular seem to allow the presence of the complementizer at $(t)$ before a subject trace. An overview of such cases may be found in Lohndal (2007).

Moreover, for yet other varieties, other complementizers and similar elements may precede the position of a subject trace. A case in point is Danish, which according to Engdahl (1986: 123) allows the item der 'there' to precede the subject trace under extraction as in (3) (attributed to Diderichsen 1966: 183).

\section{(3) Danish}

Hvem $_{\mathrm{i}}$ tror $\mathrm{du}$, at der $\mathrm{t}_{\mathrm{i}}$ har gjort det? who think you that there has done it 'Who do you think has done it?'

Danish der functions as an expletive in existential and presentational constructions, just like English there, and on this point Danish differs from most varieties of Norwegian and Swedish, which typically use det 'it' (see 
Engdahl and Laanemets 2015: $312 \mathrm{ff}$ for discussion and further references). But Danish der also has other functional uses by which it differs from its counterparts in Norwegian and Swedish. One important difference is that it can introduce subject relatives as an alternative to som, which otherwise is the only option in non-subject (nominal) relative clauses.

\section{(4) Danish}
a. manden, der/som kan tale dialect man-DEF there/SOM can speak dialect 'the man who can speak dialect'

$\begin{array}{lllll}\text { b. manden, som } / * \text { der } & \text { jeg talede dialekt } & \text { til } \\ \text { man-DEF } & \text { SOM/there } I & \text { spoke dialect } & \text { to }\end{array}$ 'the man who I spoke dialect to'

This affinity between der and som in Danish is interesting in that many Norwegian dialects allow som to precede a subject trace under long whmovement (Nordgård 1985, 1988). Across Norwegian varieties we may thus encounter the following three structures.

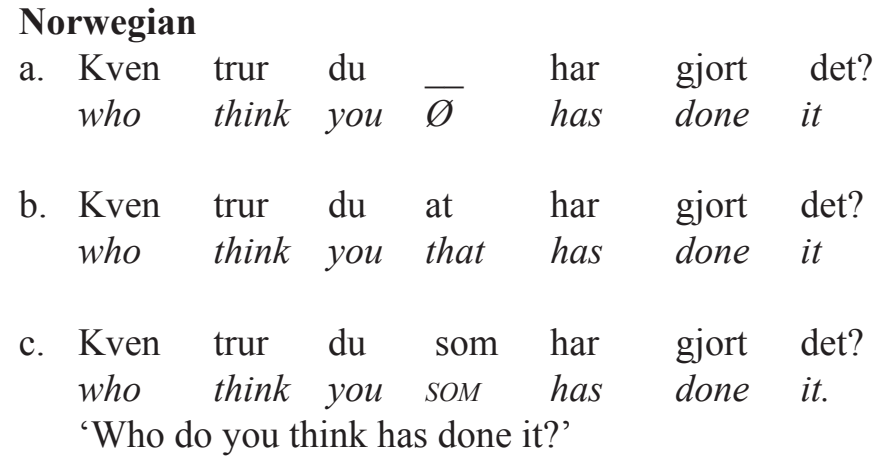

An interesting question is, of course, whether the cases of der- and sominsertion are exceptions to the that trace effect, as the complementizer (like) items do not correspond to the declarative complementizer that, a fact that can be illustrated by paraphrasing the interrogative sentences in (5) as declaratives as seen in (6). 
(6) Norwegian

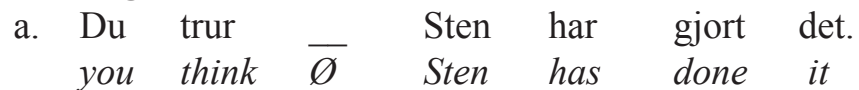

b. Du trur at Sten har gjort det. you think that Sten has done it

c. *Du trur som Sten har gjort det. you think SOM Sten has done it 'You think Sten has done it.'

Still, if we rename the that trace effect the COMP trace effect, as is quite normally done (see e.g. Pesetsky 2016), we have an adequate nomenclature for dealing with the various cases under a common approach.

In this paper we will do precisely that. We will take a closer look at various exceptions to the COMP trace effect across varieties of North Germanic, with an emphasis on data collected within the Scandinavian Dialect Syntax project (see Vangsnes 2007; Vangsnes and Johannessen 2019), both as part of the systematic questionnaire-based data collection across an evenly distributed number of locations and as part of focused NORMS ${ }^{2}$ fieldtrips to selected areas, notably the ones to Western Jutland and the Faroe Islands in 2008. Section 2 is devoted to a presentation of the systematic data collection carried out for Norwegian and Swedish dialects. In Section 3, data on Faroese are presented. In section 4 data from Western Jutlandic and Danish is compared to Faroese and Norwegian, and we raise the question whether the items used under extraction in these varieties can be regarded as resumptive elements. Section 5 sketches an analysis to capture the various facts encountered and section 6 concludes the paper.

2 NORMS is the abbreviation of the Nordic Center of Excellence in Microcomparative Syntax which was a five year project jointly financed by NOS-HS and NordForsk between 2005 and 2010. The project was a part of the Scandinavian Dialect Syntax project umbrella and involved groups of researchers at University of Tromsø, the Norwegian University of Science and Tecnhology, University of Oslo, University of Iceland, University of Aarhus, University of Lund and University of Helsinki. During the project period altogether seven dialectological fieldtrips to different areas in the North Germanic language area were organized, see http://websim.arkivert.uit.no/scandiasyn/fieldwork/ index.html. 


\section{At- and som-insertion in Norwegian and Swedish dialects}

\subsection{Initial observations}

Across varieties of Norwegian we may observe the three structures given above in (5), when an embedded $w h$-subject is extracted to the left periphery of the main clause, i.e. either: (i) no embedded complementizer, (ii) the presence of the complementizer at in the embedded left periphery, or (iii) the complementizer som in the embedded left periphery. We also noted that in the declarative paraphrases of these interrogative sentences only at (and not som) is possible, cf. (6). The same difference between atand som-insertion can be observed under wh-extraction of a non-subject. This is illustrated in (7) with a wh-object, and in (8) with a wh-adverb.

\section{(7) Norwegian}

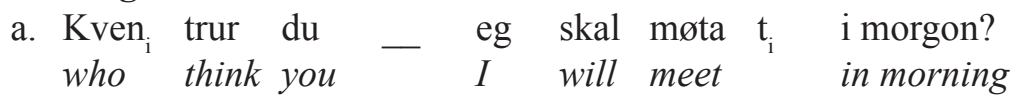

b. Kven ${ }_{\mathrm{i}}$ trur $\mathrm{du}$ at eg skal møta $\mathrm{t}_{\mathrm{i}} \mathrm{imorgon?}$ who think you that $I$ will meet in morning

c. * Kven ${ }_{\mathrm{i}}$ trur du som eg skal møta $\mathrm{t}_{\mathrm{i}}$ i morgon? who think you SOM I will meet in morning 'Who do think I will meet tomorrow?'

(8) Norwegian

$\begin{array}{llllll}\text { a. Kor } & \text { trur } \mathrm{du} & & \text { eg } & \text { skal møta } & \text { Sten } \mathrm{t}_{\mathrm{i}} \text { ? } \\ \text { where think you } & \text { I } & \text { will meet } & \text { Sten }\end{array}$

b. Kor ${ }_{\mathrm{i}}$ trur $\mathrm{du}$ at eg skal møta Sten $\mathrm{t}_{\mathrm{i}}$ ? where think you that I will meet Sten

c. *Kor ${ }_{\mathrm{i}}$ trur $\mathrm{du}$ som eg skal møta Sten $\mathrm{t}_{\mathrm{i}}$ ? where think you as I will meet Sten 'Where do you think I will meet Sten?' 
Importantly, whereas at-insertion versus som-insertion in the case of extraction of a $w h$-subject seems to be a matter of dialect variation, the non-viability of som-insertion in the other cases is not: dialects that allow (5c) do not allow (6c), (7c) and (8c). This indicates that som is not just a "replacer" for at in some dialects. Rather, it suggests that som in these dialects has certain properties that facilitate the use of it in one particular context where other dialects may use $a t$.

\subsection{Mapping the variation}

Long distance $w h$-movement of various constituents was systematically tested in the Scandinavian Dialect Syntax project and included in a questionnaire of between 150 and 250 test sentences presented to informants at a range of measure points in Norway, Sweden, Finland (the Swedish speaking parts), and to some extent the Faroe Islands. Unfortunately, the phenomenon was not investigated for Danish dialects. At most locations there were four informants who judged the individual test sentences on a Likert scale from 1 (bad) to 5 (good). The results from the questionnaires can be retrieved from the Nordic Syntax Database (NSD) (Lindstad et al. 2009; Vangsnes \& Johannessen 2019, see also list of online resources). Furthermore, the NSD interface has a map function which allows automatic generation of maps that visualize the results, and all maps that follow are such maps unless otherwise stated.

The sentence in (5a), with no complementizer, was accepted at all measure points where it was presented to the informants. This is shown in Map 1, where all the white markers indicate a mean score better than 4 on a 1-5 Likert scale at the measure point in question. 


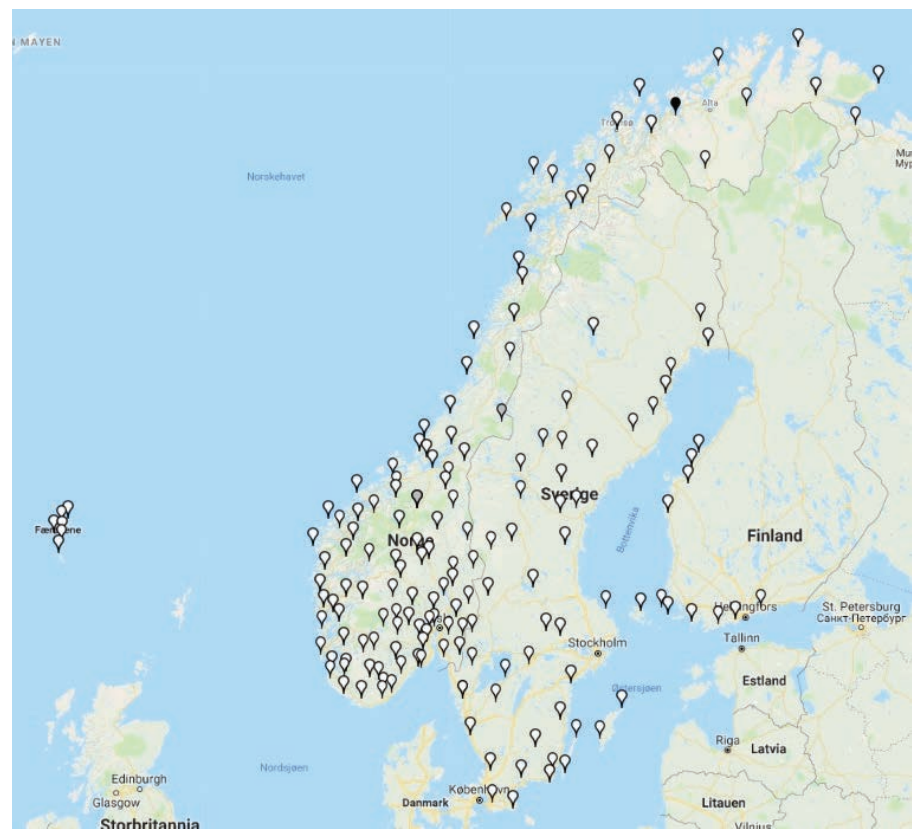

Map 1: Visualization of the NSD scores for no complementizer preceding a subject trace under wh-extraction (Kven trur du har gjort det? 'Who do you think _ has done it?'): white markers indicate high average score, grey markers indicate medium average score, black markers indicate low average score.

The sentence in (5b) with at-insertion comes out differently. This sentence is accepted at relatively few measure points, and the places in question are first and foremost found in Eastern Norway and in (Swedish-speaking) Finland. There are also some measure points where the sentence gets a medium score, which indicates that there is some variation across speakers. The white markers in Map 2 indicate measure points with a high medium score $(\mathrm{n}>4)$, grey markers a medium score $(\mathrm{n} \approx 3)$, whereas black markers indicate a low medium score $(\mathrm{n}<2)$. 


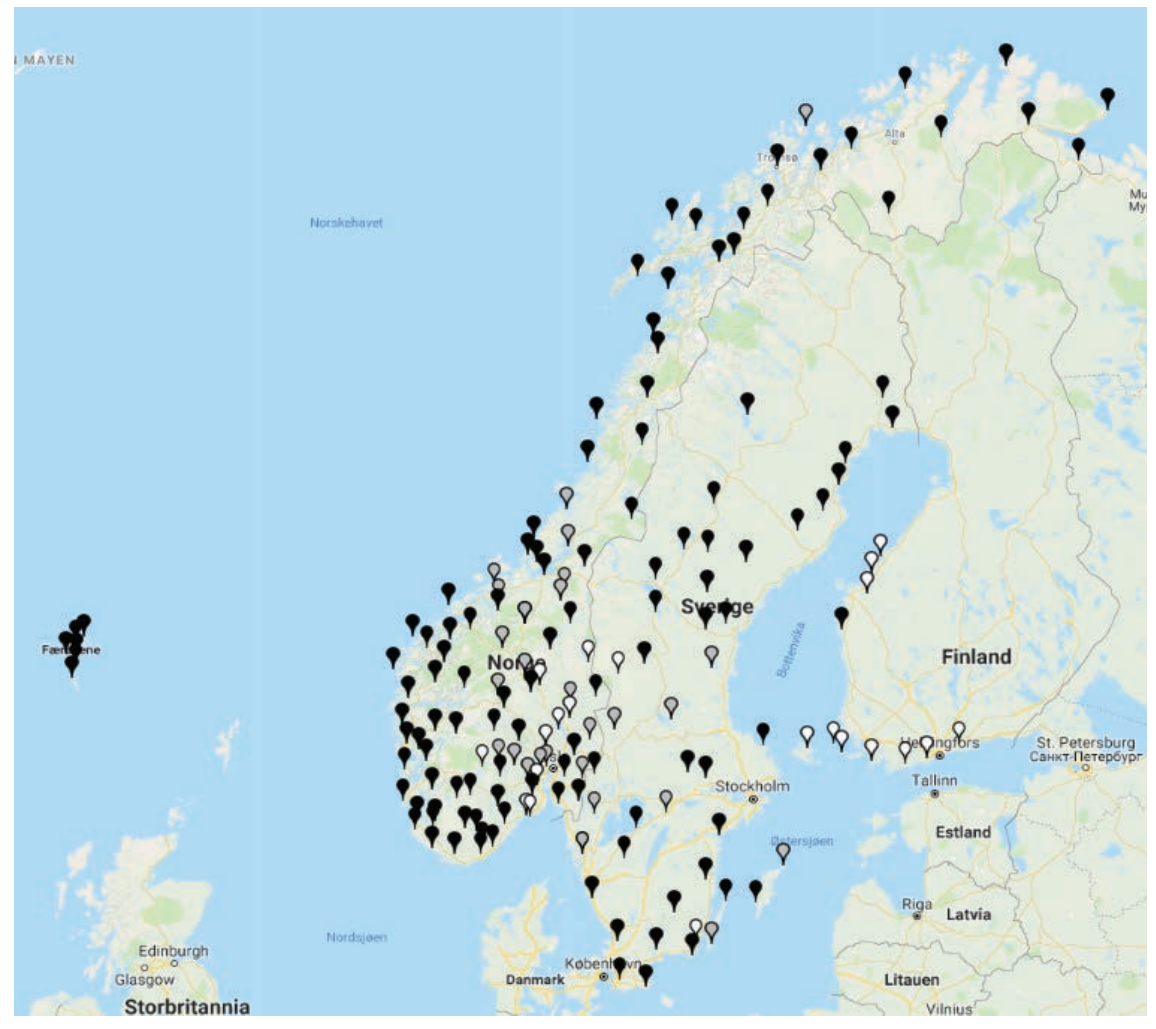

Map 2: Visualization of the NSD scores for a that complementizer preceding a subject trace under wh-extraction (Kven trur du at har gjort det? 'Who do you think that _has done it?'): white markers indicate high average score, grey markers indicate medium average score, black markers indicate low average score.

If we then compare at-insertion with som-insertion, we see that sentence (5c) is by and large accepted in all of Northern Norway, and also to a considerable extent in Central and Western Norway, whereas, on the most part, it is not accepted in Eastern Norway and the Swedish language area (including the measure points in Finland). There are no data on Faroese for this sentence in NSD. 


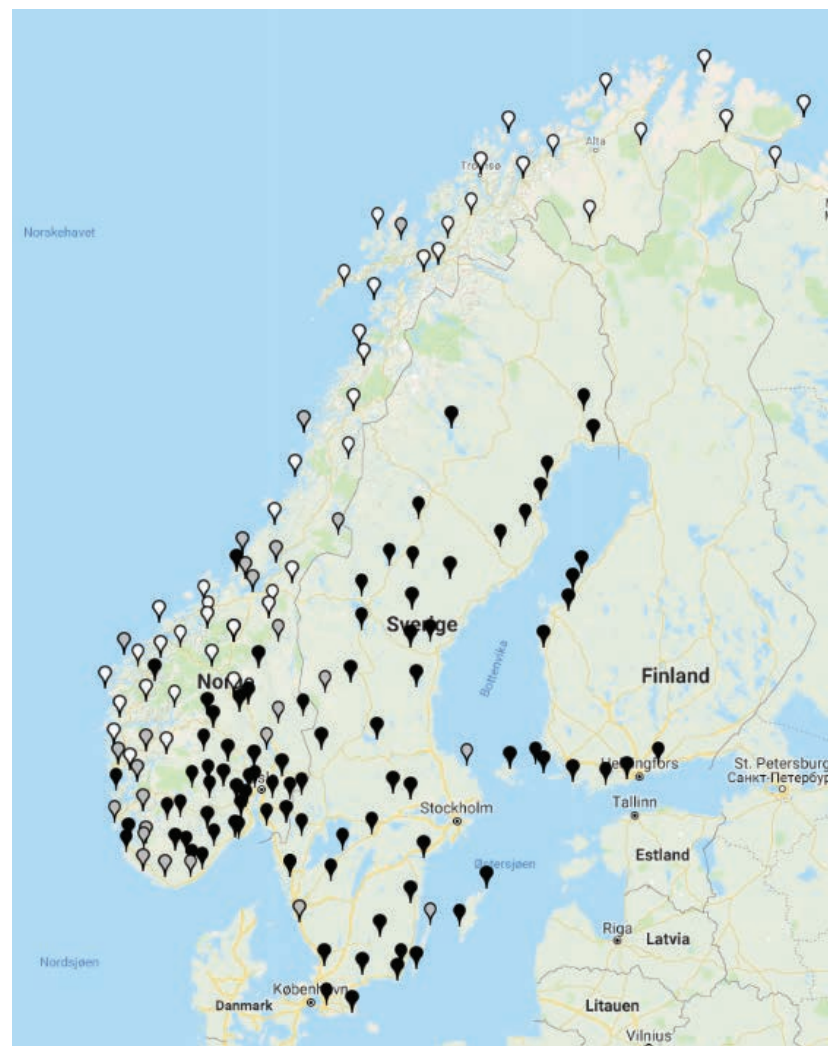

Map 3: Visualization of the NSD scores for a som complementizer preceding a subject trace under wh-extraction (Kven trur du som har gjort det? 'Who do you think SOM _ has done it?'): white markers indicate high average score, grey markers indicate medium average score, black markers indicate low average score.

If we ignore measure points with a medium score and only look at those with a high score for at-insertion and som-insertion, a fairly clear pattern of complementarity emerges. In Map 4, the grey markers indicate locations with a high score for (5c) (som-insertion) whereas the blue markers indicate locations with a high score for (5b) (at-insertion). 


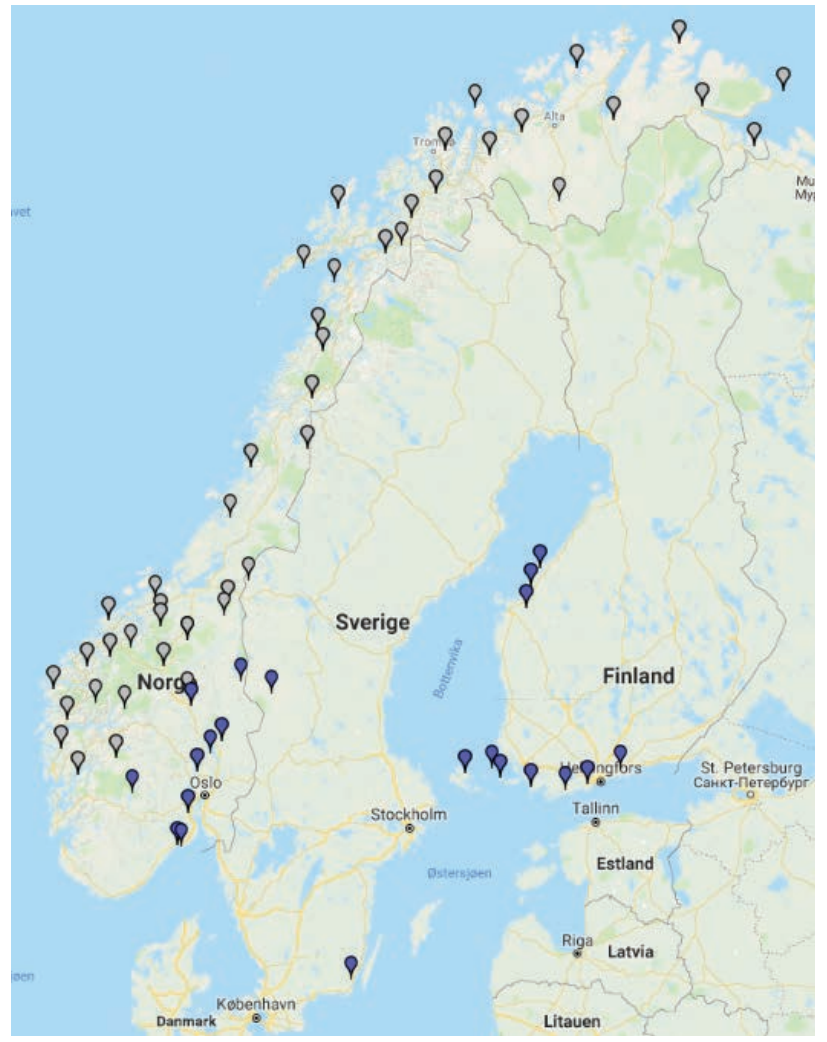

Map 4: Visualization of high NSD score for at-insertion (blue markers) versus som-insertion (grey markers) before a subject trace under $w$ h-extraction

After the data collection had commenced the sentence in (9) was added to the questionnaire.

(9) Norwegian

Kven sa du at ikkje hadde komme?

who said you that not had come

'Who did you say hadn't come?'

In (9), an adverbial follows the complementizer, in this case the negative sentence adverb ikkje 'not'. A higher acceptance for this sentence could be related to the so-called "adverb (intervention) effect"; it has been noted for English that an intervening adverb/adverbial facilitates that-insertion, see Lohndal (2009: 208f) and Pesetsky (2016: 12f) who give the following examples from Culicover (1993): 
(10) a. Robin met the man who Leslie said that for all intents and purposes _ was the mayor of the city.

b. I asked what Leslie said that in her opinion _ had made Robin give a book to Lee.

The sentence in (9) does indeed obtain a higher acceptance rate in Eastern and Central Norway than (5b) (compare maps 2 and 5).

\section{(11) Norwegian}

Jon sa at (ikkje) Per (ikkje) hadde komme.

Jon said that not Per not had come

'Jon said that Per hadn't come.'

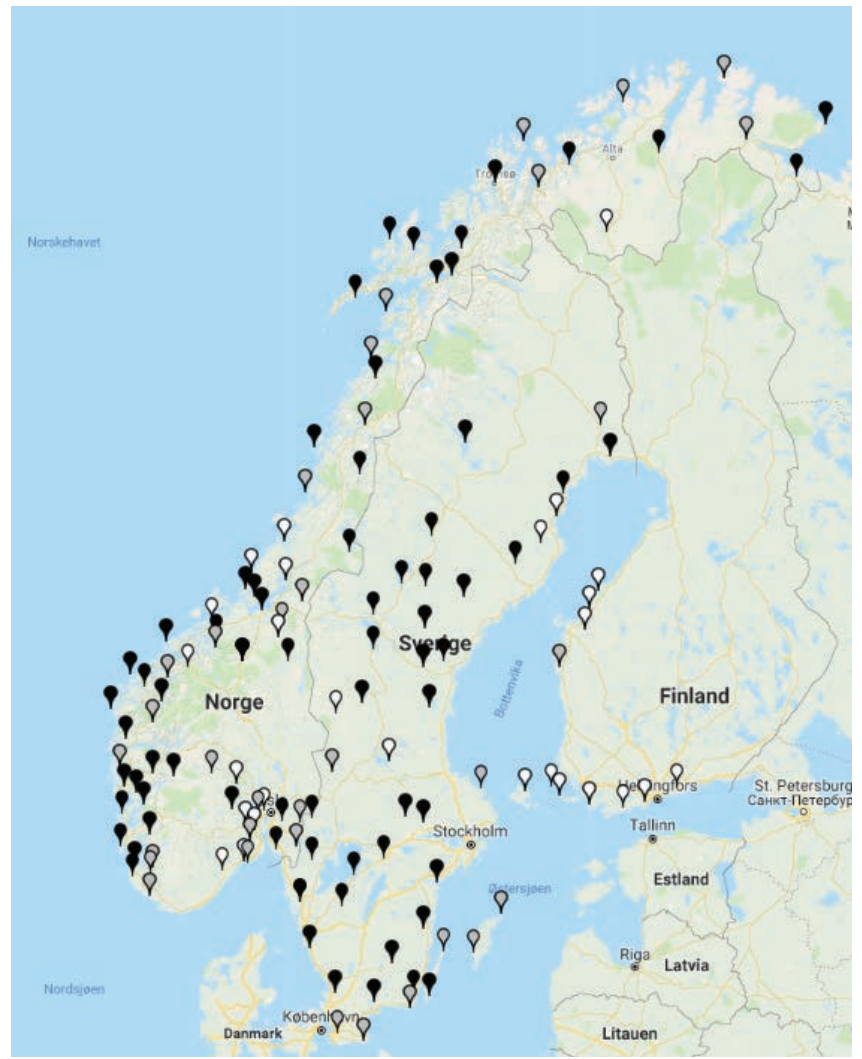

Map 5: Visualization of the NSD score for at-insertion before negation under extraction of a wh-subject (Kven sa du at ikkje hadde komme? 'Who did you say that had not come?'): white markers indicate high average score, grey markers indicate medium average score, black markers indicate low average score. 
In Map 6, the high mean scores for both test sentences with at-insertion (5b) and (9) - are displayed together:

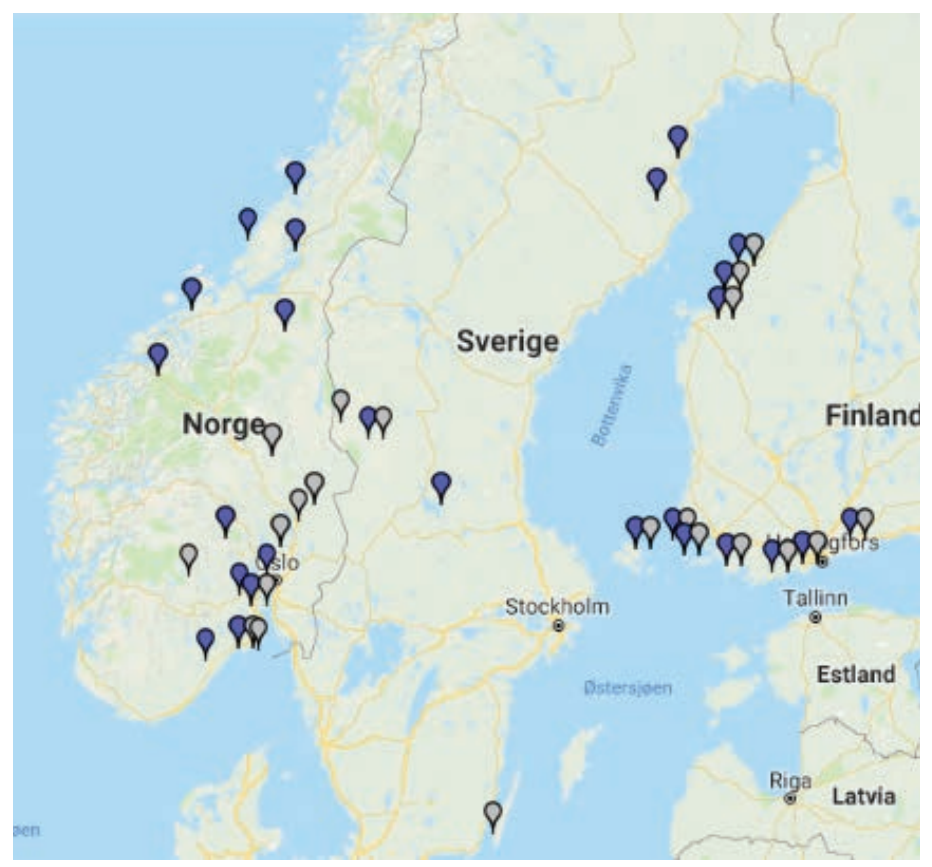

Map 6: Visualization of the NSD high scores for the two sentences with atinsertion before a subject trace: Kven sa du at ikkje hadde komme? 'Who did you say that hadn't come' (blue) vs. Kven trur du at har gjort det? 'Who do you think that has done it? (gray)

Unfortunately, for the test sentence in (9) we do not have a complete data set from Norway (since it was not included from the start). Furthermore, we do not have data for a version with som-insertion nor for one with an embedded complementizer. And, importantly, whereas the English adverbial in (10) unequivocally precedes the subject trace and hence intervenes between it and the complementizer, we cannot say for sure whether the adverb in (9) precedes or follows the subject trace. As the examples in (11) illustrate, an unmoved subject may either precede or follow the negation.

Accordingly, it is not entirely clear how sentence (9) relates to the adverb effect observed for English. Still, when we consider the geographical area that the sentence "adds" to the picture, namely Central Norway, we may note that this is an area known for allowing negation - in the 
form $i t j$ - to precede subjects to a greater extent than in other varieties of Norwegian (see Hellan 1996, Østbø Munch 2013: 243ff, Garbacz 2014: $308 \mathrm{ff}$ ), possibly as an effect of cliticization to items in or moved to the left periphery (Hellan 1996). Accordingly it may be the case that the Central Norwegian speakers who accept (9) interpret the structure as one where (i) the negation precedes the subject trace, (ii) is clitic, and (iii) needs an overt complementizer as a host.

In hindsight, the addition of the test sentence in (9) seems to have created more confusion than clarity, and it is quite obvious that several issues need to be investigated further. In any event, Map 7 displays all measure points at which either of the two sentences probing at-insertion and/or the one with som-insertion receive a high mean score.

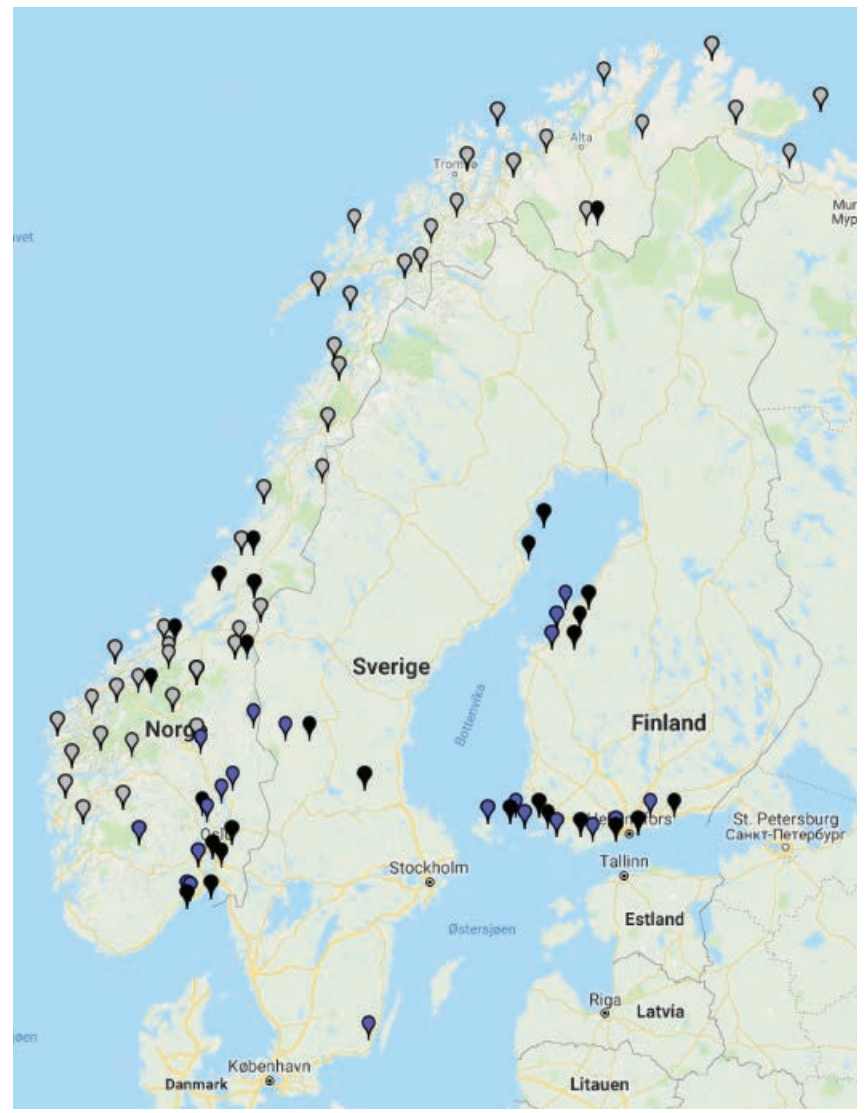

Map 7: High mean score for som-insertion (gray markers) and at-insertion under extraction from a transitive embedded clause (blue markers), and at-insertion before negation (black markers). 
Despite the noise in the data created by the test sentence in (9), the maps above have shown, on the one hand, that violations of the COMP trace effect appear to be acceptable among a fair number of speakers of Norwegian and Swedish dialects and, on the other hand, that som-insertion and at-insertion to a high degree are in complementary distribution.

\subsection{Nordgård's Condition}

The last point relates to the observation in Nordgård (1985) that dialects that allow non-V2 in matrix $w h$-questions, i.e. of the kind given in (12), also allow som-insertion under extraction of a $w h$-subject.

\section{(12) Norwegian}
a. Kven som kom? who som came 'Who came?'
b. Kva du sa? what you said 'What did you say?'

Nordgård (1985: 35) formulates this as the following condition (somewhat adapted here; see also Westergaard, Vangsnes, and Lohndal 2017):

\section{Nordgård's Condition:}

A dialect allows non-inverted word order in matrix wh-questions iff the dialect allows insertion of the complementizer som under extraction of the embedded subject.

Notice that the condition is unidirectional. It does not state that a dialect that allows som-insertion must allow non-V2 in matrix wh-questions too.

The validity of Nordgård's Condition is discussed in Westergaard, Vangsnes and Lohndal (2017). In Map 8, which is taken from that paper, letters A-D indicate areas of Norway where non-V2 is allowed in matrix wh-questions, whereas in the areas marked '*' and '?' such constructions are not allowed, or the picture is unclear, respectively. When this map is juxtaposed to Map 3 (with only the Norwegian markers to enhance clarity), which shows the results for sentence $(5 \mathrm{c})$ with $s o m$-insertion under $w h$-extraction, we see that there is a fairly good match, in particular when we also count the locations with a medium score. 


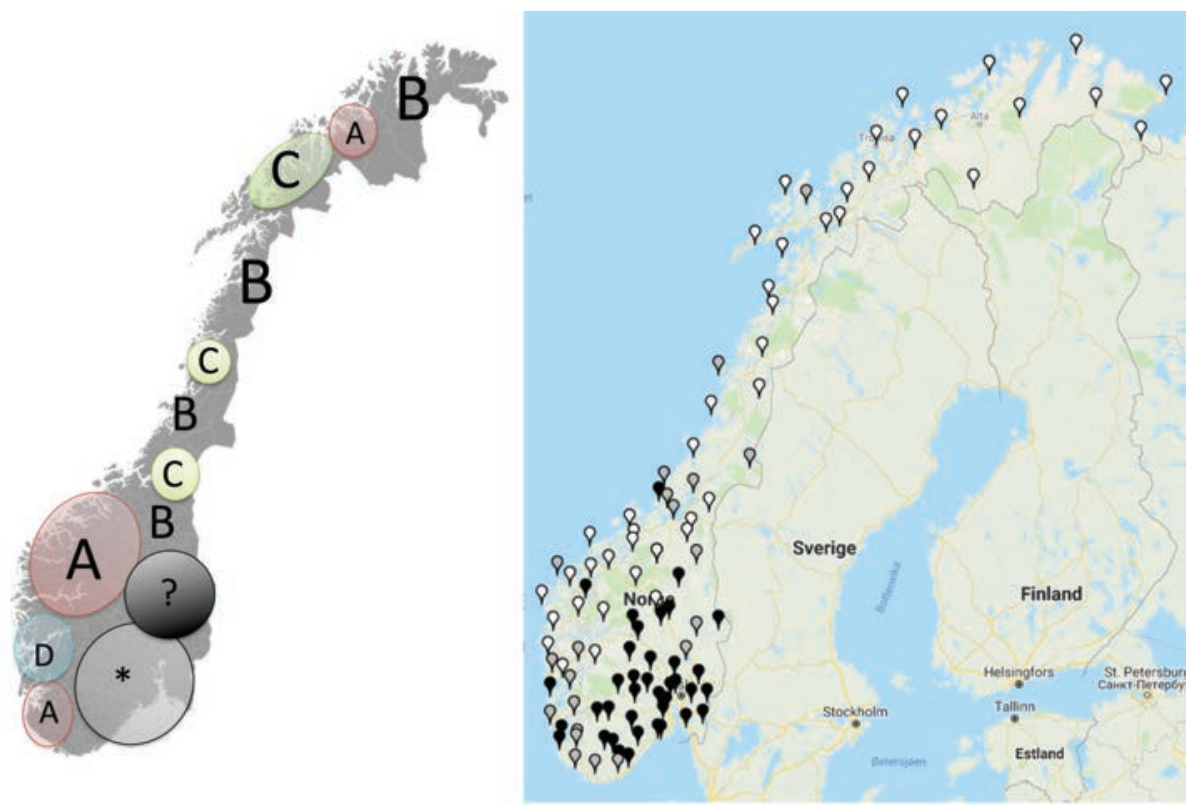

Map 8: Map (left) from Westergaard, Vangsnes \& Lohndal (2017) showing the distribution of various types of grammars (A-D) that allow non-V2 in matrix whquestions and not $(*)$ versus map (right) showing varieties that allow som-insertion under extraction of an embedded $w h$-subject (white markers $=$ high mean score, gray markers $=$ medium mean score, black markers $=$ low mean score).

Including locations with a medium mean score can be justified by reference to the general tendency that extraction examples with no embedded complementizer are judged better than examples with an embedded complementizer even under object extraction (see Cowart 1997; Hawkins 2004; Bentzen 2014; Schippers 2017).

The relevance of Nordgård's Condition for the present paper will become clearer below, after we have also considered Faroese and Western Jutlandic as well as Danish.

\section{Faroese at-, sum- and ið-insertion}

In NSD there are two test sentences probing long movement of a whsubject, one with no embedded complementizer and one with the embedded complementizer at. The test sentences are: 
(13) Faroese

$\begin{array}{llll}\text { Fótboltslandsliðið } & \text { fer } & \text { til } & \text { Skotlands } \\ \text { football-country-team } & \text { goes } & \text { to } & \text { Scotland }\end{array}$

Hvør væntar tú fer við?

who expect you goes with

'The national football team is going to Scotland. Who do you expect to go?'

$\begin{array}{llllll}\text { (14) Ein } & \text { mynd } & \text { er } & \text { tikin } & \text { úr } & \text { Listaskálanum } \\ a & \text { painting } & \text { is } & \text { taken } & \text { from } & \text { art gallery-DEF }\end{array}$

Hvør heldur tú, at hevur gørt hetta? who think you that has done this

'A painting has been taken from the art gallery. Who do you think has done this?'

The first sentence - with no complementizer - was presented to 42 informants in six locations, and the result is a high mean score at all locations. At a more detailed level, 33 of the informants give it the highest score (5), six give it a medium score (3), and three give it low score (1).

In contrast, the second sentence - with at-insertion - was presented to 44 informants at the same six locations, and at all locations it obtains a low mean score. In this case, 33 of the informants give it the lowest score (1), three give it a medium score (3), whereas eight informants judge it with the highest score (5). Map 9 indicates where the six Faroese measure points are from south to north: Tvørøyri, Sandur, Tórshavn, Vágar, Fuglafjörður, and Klaksvík.

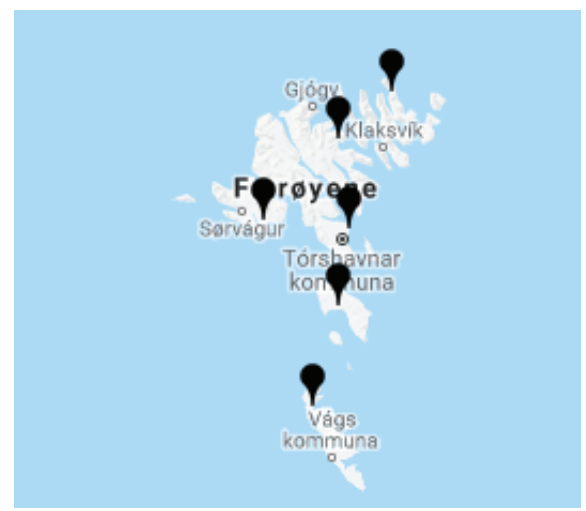

Map 9: The six Faroese measure points in the Nordic Syntax Database 
During the NORMS fieldtrip to the Faroe Islands in August 2008, other examples of long subject extraction were also tested, including additional complementizers in the embedded left periphery, namely the set given in (15).

(15) Faroese

\begin{tabular}{|c|c|c|c|c|c|c|}
\hline a. & $\begin{array}{l}\text { Hvør } \\
\text { who }\end{array}$ & $\begin{array}{l}\text { trýrt } \\
\text { think }\end{array}$ & $\begin{array}{l}\text { tú } \\
\text { you }\end{array}$ & - & $\begin{array}{l}\text { hevur } \\
\text { has }\end{array}$ & $\begin{array}{l}\text { gørt } \\
\text { done }\end{array}$ \\
\hline b. & $\begin{array}{l}\text { Hvør } \\
\text { who }\end{array}$ & $\begin{array}{l}\text { trýrt } \\
\text { think }\end{array}$ & $\begin{array}{l}\text { tú } \\
\text { you }\end{array}$ & $\begin{array}{l}\text { at } \\
\text { that }\end{array}$ & $\begin{array}{l}\text { hevur } \\
\text { has }\end{array}$ & $\begin{array}{l}\text { gørt } \\
\text { done }\end{array}$ \\
\hline c. & $\begin{array}{l}\text { Hvør } \\
\text { who }\end{array}$ & $\begin{array}{l}\text { trýrt } \\
\text { think }\end{array}$ & $\begin{array}{l}\text { tú } \\
\text { you }\end{array}$ & $\begin{array}{l}\text { sum } \\
\text { SOM }\end{array}$ & $\begin{array}{l}\text { hefur } \\
\text { has }\end{array}$ & $\begin{array}{l}\text { gørt } \\
\text { done }\end{array}$ \\
\hline d. & $\begin{array}{l}\text { Hvør } \\
\text { who }\end{array}$ & $\begin{array}{l}\text { trýrt } \\
\text { think }\end{array}$ & $\begin{array}{l}\text { tú } \\
\text { you }\end{array}$ & $\begin{array}{l}\text { ið } \\
\text { ið }\end{array}$ & $\begin{array}{l}\text { hevur } \\
\text { has }\end{array}$ & $\begin{array}{l}\text { gørt } \\
\text { done }\end{array}$ \\
\hline
\end{tabular}

The version in (15a) has no embedded complementizer, indicated by the empty line. In (15b), we find the declarative complementizer at corresponding to English that. In (15c), we have the complementizer sum which corresponds to som in Mainland North Germanic (cf. above). Finally, in (15d), the item id appears before the trace position of the extracted $w h$-subject: according to the online dictionary Sprotin (see list of online resources), this item has a variety of complementizer and adverbial uses and, crucially, it is an alternative to sum in relative clauses. The use in relative clauses is addressed in Thráinsson et al. (2012: 196) and they also note that $i$ ¡ optionally may follow the wh-constituent in embedded wh-clauses (Thráinsson et al. 2012: 196, 303f). Importantly, not indicated in the dictionary, nor in Thráinsson et al. (2012), but confirmed by Hjalmar Petersen (p.c.), ið cannot be used in regular declarative clauses, i.e. as an alternative to $a t$.

The sentences in (15) were presented to 43 informants who come from the same six places as the NSD data come from. No scale was used, and 
it was simply recorded whether or not informants accepted the sentences. Notes were taken for cases in which the informant expressed uncertainty. ${ }^{3}$

As with the NSD data, no clear geographical patterns were found, and Table 1 summarizes how the four versions of the sentence in (15) were judged by the 43 informants.

\begin{tabular}{|l|c|l|c|c|}
\hline$(15)$ & COMP & Test sentence & n of 43 informants & $\%$ \\
\hline a. & 0 & Hvør trýrt tú _ hevur gørt tað? & 43 & 100 \\
\hline b. & $a t$ & Hvør trýrt tú at hevur gørt tað? & 2 & 4.7 \\
\hline c. & sum & Hvør trýrt tú sum hefur gørt tað? & 5 & 11.6 \\
\hline d. & ið & Hvør trýrt tú io hevur gørt tað? & 16 & 37.2 \\
\hline
\end{tabular}

Table 1: Results from the NORMS Føroyar investigation of long $w h$-movement

To little surprise, all informants accepted the version with no embedded complementizer (15a). Only two informants accepted the version in (15b) with at-insertion, and this is line with the NSD data mentioned above. Furthermore, very few informants - only five - accepted sum-insertion (15c), but interestingly 16 of the 43 informants found example (15d) with ið-insertion acceptable. Two of them also accepted sum-insertion whereas two others also accepted $a t$-insertion. No geographical pattern was detected.

This indicates that Faroese also allows exceptions to the COMP trace effect to some degree, presumably idiolectally rather than dialectally, and typologically speaking we can therefore group Faroese with Western, Central, and Northern Norwegian dialects in that the inserted C-element is an item otherwise used in relative clauses, rather than the regular declarative complementizer.

At this point let us turn to Western Jutlandic and Danish.

\section{Western Jutlandic and Danish meets Norwegian and Faroese: complementation or resumption?}

As noted in the introduction, Engdahl (1986) pointed out that Danish allows der-insertion under extraction of a $w h$-subjects. During the NORMS

$\overline{3}$ I did the interviews in Tórshavn, Tvørøyri, Fuglafjørður, and Klaksvík myself, and I am indebted to Gunnar Hrafn Hrafnbjargarson for collecting responses from Sandur and Vágar. In the raw data disapproval of the sentences is assigned the value 0 and approval the value 1 whereas uncertainty is rendered as 0.5 . Out of the total of 172 judgments ( 4 x 43) there were only four uncertain cases, one for at-, two for sum-, and one for $i ð-$ insertion. The figures in Table 1 reflect the positive judgments only. 
fieldtrip to Western Jutland in January 2008, organized by Henrik Jørgensen and Sten Vikner, such der-insertion under extraction of an embedded subject to the matrix left periphery was investigated.

Altogether eight dialect speakers were interviewed on the topic - two from Sevel, four from Spjald, and two from Thorsminde - and all of them accepted the insertion of the item doe (corresponding to Standard Danish der 'there') at the beginning of the embedded clause when the embedded wh-subject was moved to the front of the main clause as in (16b).

\section{(16) Western Jutlandic}

a. $\mathrm{Hu}$ manne trowe du _ snakke dialect i Spjald? how many think you - talk dialect in Spjald

b. $\mathrm{Hu}$ manne trowe du dæ snakke dialekt i Spjald? how many think you there speak dialect in Spjald

c. ??Hu manne trowe du som snakke dialekt i Spjald? how many think you som talk dialect in Spjald All: 'How many do you think speak dialect in Spjald'

Sentence (16a) with no doe-insertion in the embedded clause was also accepted by all informants, whereas the example in (16c) with sominsertion rather than $d a$-insertion was met with considerable skepticism. The relevance of probing (16c) should be obvious given the Norwegian data.

In addition to $d a$-insertion under wh-extraction, the informants also accepted $d o e$-insertion under long topicalization.

\section{(17) Western Jutlandic}

a. Dem folk hæ trowe a _ snakke jysk. them people here think I speak jutlandic

b. Dem folk hæ trowe a dæ snakke jysk. them people here think I there speak jutlandic

c. *Dem folk hæ trowe a som snakke jysk. them people here think I som speak jutlandic All: 'These people I believe to speak Jutlandic.' 
In fact, when given (16a) and (17a), several of the informants reacted spontaneously by inserting doe in line with (16b) and (17b).

Insertion of der under long topicalization is known from Standard Danish too. Engdahl (1985: 21) provides the example in (18).

\section{(18) Danish}

Vennen, (som) han påstod at der havde lånt friend-DEF SOM he claimed that there had borrowed bogen, var forsvundet. book-DEF was disappeared

'The friend that he claimed had borrowed the book had disappeared.'

The fact that der-insertion under subject extraction has been noted for Standard Danish might suggest that it is a general property of Danish, and not restricted to just some varieties. Unfortunately, the matter was not investigated in the Danish subproject of the Scandinavian Dialect Syntax project (DanDiaSyn).

Notice, furthermore, that both in (18) and in (3), repeated here for convenience, der in fact co-occurs with at.

\section{(3) Danish}

Hvem $_{\mathrm{i}}$ tror $\mathrm{du}$, at der $\mathrm{t}_{\mathrm{i}}$ har gjort det? who think you that there has done it 'Who do you think has done it?'

On the other hand, co-occurrence of at with Norwegian som and Faroese id is not acceptable, as illustrated in (19) and (20). The judgment of the Norwegian example is that of the author and Merete Anderssen (p.c.); the $\%$ sign marks the Faroese example as idiolectal (cf. above), and the nonviability of at in the structure has been confirmed by Hjalmar Petersen (p.c.).

\section{(19) Norwegian}

Kven trur du (*at) som har gjort det? who think you that som has done it 'Who do you think has done it?' 
(20) Faroese

$\begin{array}{lllllll}\text { \%Hvør trýrt tú } & \text { (*at) } & \text { ið } & \text { hevur gørt tað? } \\ \text { who think you that } & \text { ið } & \text { has } & \text { done it }\end{array}$

'Who do you think has done it?'

This means that although Danish der parallels dialectal Norwegian som and idiolectal Faroese $i ð$, in that they are all used in relative clauses, Danish der is different on at least two points: (i) it can co-occur with at in extraction cases, and (ii) it is strongly subject-related and only used in subject relatives (whereas som and $i ð$ can also be used in object relatives). The use of der as an expletive may be added as a third distinguishing property, possibly related to the subject property.

Engdahl (1985) interprets Danish der-insertion as resumption rather than complementation, i.e. that der fills the trace position rather than precedes it. (See also Lohndal 2007: 51ff for discussion.) The partial parallelism with som-insertion in Norwegian and $i \delta$-insertion in Faroese raises the question whether both som-insertion and $i \delta$-insertion are a matter of resumption rather than complementation. If that were the case, the use of these items would not represent exceptions to the COMP-trace effect, and we would also have an explanation for why the items cannot be used in declarative paraphrases of the interrogative sentences in question (see above). In turn, the main challenge would be to understand what makes the items viable for resumption and, furthermore, what prompts resumption in the varieties in question. On that note, let us sketch an analysis.

\section{Analysis}

An important basic fact is that absence of a COMP element under subject extraction is accepted by everybody, as seen in Map 1. That means that the insertion of a COMP element appears to be optional, even for individuals who accept it. This sheds doubt on the idea advanced in Lohndal (2009: 223) (based on Boeckx 2008) that the COMP-trace effect and lack thereof can be captured by a parameter which either requires or prohibits the insertion of a COMP element. It seems that a weaker statement is called for, whereby insertion of various COMP elements is allowed, but not required, by certain grammars. The basis for this optionality needs to be investigated further, but for the lack of a better explanation we will here assume that what triggers COMP insertion is a pragmatic preponderance in certain cases, to mark the left edge of the embedded clause. 
The idea argued for in the present paper is that the variation observed is an effect of the varying properties of the COMP elements that we have encountered, and how they relate to a basic CP-FinP-TP structure. We will employ a distinction between head $\left(\mathrm{X}^{\circ}\right)$ and specifier (XP), and, on a fairly traditional view of complementizers, at, som, and ið will be considered $\mathrm{X}^{\circ}$ whereas der will be treated as an $\mathrm{XP}$, given its use as an expletive. The latter runs counter to the proposal in Vikner (1991) that expletive der is an $\mathrm{XP}$ but relative der an $\mathrm{X}^{\circ}$ (see also Engdahl and Laanemets 2015), but here we advance a uniform treatment of the item across uses.

In short, at will be taken to be merged in $\mathrm{C}$, whereas Norwegian som and Faroese $i ð$ are merged in $\mathrm{T}$ and subsequently moved to $\mathrm{C}$ (via Fin). Following Engdahl (1985) der is considered a resumptive element merged in the position of the subject trace, i.e. in Spec-T. It is subsequently moved to Spec-Fin to license FinP. On this basic approach, with the structures given in (21), at may cooccur with der in Danish but not with som and ið in Norwegian and Faroese.

a. Danish

wh-subject ${ }_{\mathrm{i}} \ldots\left[_{\mathrm{CP}} \mathrm{t}_{\mathrm{i}}\left[_{\mathrm{C}}\right.\right.$ at $]$

$\left[_{\mathrm{FinP}}\left[\operatorname{der}_{\mathrm{i}-\mathrm{j}}\right] \quad\left[_{\mathrm{TP}} \mathrm{t}_{\mathrm{j} \mathrm{T}} \cdots\right.\right.$

\section{b. Norwegian/Faroese}

$w h$-subject $_{\mathrm{i}} \ldots\left[_{\mathrm{CP}} \mathrm{t}_{\mathrm{i}}\left[_{\mathrm{C}}\right.\right.$ som/ið $\left.\delta_{\mathrm{i}-\mathrm{j}}\right] \quad\left[_{\mathrm{FinP}} \mathrm{t}_{\mathrm{i}-\mathrm{j}} \quad\left[_{\mathrm{TP}} \mathrm{e}_{\mathrm{i}} \mathrm{i}_{\mathrm{T}} \mathrm{t}_{\mathrm{i}-\mathrm{j}}\right] \ldots\right.$

As indicated by the indices, we also entertain the idea that som and ið are resumptive elements in that they are co-referent with the moved whsubject. When merged in $\mathrm{T}$, this facilitates the interpretation of the moved $w h$-subject in T. This property of som and $i ð$ is necessarily shared by all varieties and reflects their use as relative markers, but what is special in varieties that allow insertion in the case of $w h$ - extraction is that som and $i$ ' are also capable of licensing C. Given 'Late Merge' ("move-over-merge") (see van Gelderen, 2008, and references cited there) once som or ið are merged in $\mathrm{T}$ it will render the merger of at in $\mathrm{C}$ obsolete, as the preferred next step is to move som/id there. ${ }^{4}$ A detail concerning relative clauses is that we will take them to be FinPs rather than CPs. On that account, relative som will appear in Fin across varieties irrespective of whether we are dealing with subject or object relative clauses.

4 An alternative non-movement approach like for instance Nanosyntax (see Baunaz \& Lander, 2018) would be to say that som/ið spell out both C and T whereas at only spells out $\mathrm{C}$, and som/ið therefore "wins" over at since it is a better match (according to the Elsewhere Principle). 
On this approach, the fact that at does not co-occur with som and $i ð$ is a matter of competition. In and of itself, that is a grammar internal account which does not automatically explain the complementary distribution of at-insertion and som-insertion across grammars. In varieties where som does not license $\mathrm{C}$, but presumably still licenses $\mathrm{T}$ and Fin ( $q u a$ relative marker), i.e. in Eastern Norwegian and (Fenno)Swedish, co-occurrence of at (in C) with som (in T) should, in principle, be allowed.

In order to account for why that does not happen we will again point out the optionality of COMP-insertion. What triggers insertion of at or som under extraction of a wh-subject is not fully understood, but, as noted above, we assume that there exists some pragmatic preponderance of marking the boundary of the embedded clause. As such, the trigger relates to the (embedded) $\mathrm{C}$, not to $\mathrm{T}$ (or Fin), and it is the property of the $\mathrm{C}$-licensing element that is important. In dialectal Norwegian and idiolectal Faroese the grammar then offers an item (som/ið) which can both license $\mathrm{C}$ and facilitate the interpretation of the moved $w h$-subject, and this item is therefore chosen over at.

Further detailed motivation for this story needs to be worked out, in particular concerning what role the resumptive nature of som and $i ð$ plays. Furthermore, the reason why dialectal Norwegian som and idiolectal Faroese id have developed their C-licensing capacity may appear rather mysterious, but as hinted at in Westergaard, Vangsnes \& Lohndal (2017)(regarding som) it can be seen as a natural development on a grammaticalization cline whereby som, over time, starting out as a comparative marker, has extended its use to functions associated with higher parts of the clausal spine. ${ }^{5}$ A next step on the cline, argued for by Westergaard, Vangsnes \& Lohndal (2017) is the capacity of (dialectal) Norwegian som to license matrix C in subject wh-questions as in (22), cf. Nordgård's Condition above.

Norwegian

Kem som gjorde det?

who SOM did it

'Who did it?'

This approach underscores the unidirectional nature of Nordgård's Condition: the existence of varieties that allow som-insertion (and similar) under extraction of a $w h$-subject but not non-V2 in matrix $w h$-questions

5 See also Brandner (2017) and Brandner \& Bräuning (2013) for similar ideas regarding (dialectal) German wo. 
is expected as they represent a particular stage in the grammaticalization process. "Idiolectal Faroese" would be a case in point. However, on the present account, Danish and Western Jutlandic represent a typologically different variety, as the morphosyntactic status of der/doe is different from that of som/id.

\section{Conclusion}

In this paper we have looked at COMP trace effects across varieties of North Germanic, i.e. cases where an element appears in the left periphery of the embedded clause when an embedded $w h$-subject is moved to the left periphery of the matrix clause. Using the questionnaire data available in the Nordic Syntax Database we have seen that, in some areas of Norway (Eastern) and Sweden, insertion of the complementizer at( $t)$ is accepted by the participating speakers, whereas, in a largely non-overlapping area in Norway (Northern, Central, Western), the item som is accepted by a large number of the participants. Crucially, all speakers, including those who allow the insertion of a left peripheral element, accept versions of the test sentence with no element, which is an important observation pointing to the fact that the COMP trace structure is optional. In addition to the Norwegian and Swedish speakers, we also saw that some speakers of Faroese allow the insertion of the item $i d$ in corresponding cases. We also discussed Western Jutlandic and Danish which appears to allow the item dce/der under extraction of a $w h$-subject.

The analysis developed builds on the observation that COMP insertion is optional: Sometimes, for some speakers, a need to mark the left edge of the embedded clause is prompted, and that leads to the insertion of a COMP element. Furthermore, we pointed out that whereas at can cooccur with der in Danish, co-occurrence between at and som (Norwegian) and ið (Faroese) is not possible. Given a basic C-Fin-T(-v-V) structure we argued that the incompatibility between at and som/ið is an effect of the latter two being merged in $\mathrm{T}$ and moved to $\mathrm{C}$ via Fin in dialectal Norwegian and idiolectal Faroese: when the left edge of the embedded clause is explicitely marked som/ið are preferred over at in these varieties. The association with Fin for these elements relates to their use as relative markers and their association with $\mathrm{C}$ relates to a presumed grammaticalization path. Whereas at, som, and ið all are complementizers and hence heads, Danish der is argued to be an XP merged in Spec-T, and like som and $i ð$ it is a relative marker which resumes the moved $w h$-subject. Since der does not move, at 
may be merged in $\mathrm{C}$ to mark the left edge of the embedded clause.

Further details concerning COMP trace effects in North Germanic await elaboration, both when it comes to empirical facts and theoretical treatment. Unveiling further details about Faroese $i ð$-insertion would be interesting, and a systematic investigation of the phenomenon across varieties of Danish appears particularly desirable, as it would add potentially valuable comparative data given that the element involved (der), at least on the present account, has a different status compared to the elements used in other varieties of North Germanic.

\section{Online resources}

The Nordic Syntax Database: https://tekstlab.uio.no/nsd.

Sprotin (Faroese online dictionary): https://sprotin.fo/dictionaries.

\section{References}

Baunaz, Lena \& Eric Lander. 2018. Nanosyntax: The basics. In Lena Baunaz et al. (eds.) Exploring nanosyntax. 3-56. New York: Oxford University Press.

Bentzen, Kristine. 2014. Subject and object extraction from embedded clauses. NALS Journal, vol. 1.

Boeckx, Cedric. 2008. Bare syntax. Oxford: Oxford University Press.

Brandner, Ellen. 2017. Re-thinking re-categorization: Is that really a complementizer? Evidence from long wh-extraction for the contrary view. Unpublished manuscript, University of Stuttgart.

Brandner, Ellen \& Iris Bräuning. 2013. Relative wo in Alemannic: only a complementizer? Linguistische Berichte 234. 131-169.

Cowart, Wayne. 1997. Experimental syntax: Applying objective methods to sentence judgments. Thousand Oaks, CA: SAGE Publications.

Culicover, Peter W. 1993. Evidence against ECP accounts of the that-t effect. Linguistic Inquiry 24. 557-561.

Diderichsen, Poul. 1966. Elementcer Dansk Grammatik. København: Gyldendahl. Engdahl, Elisabet. 1985. Parasitic gaps, resumptive pronouns and subject extractions. Linguistics 23. 3-44. doi:10.1515/ling.1985.23.1.3.

Engdahl, Elisabet. 1986. Constituent questions: The syntax and semantics of questions with special reference to Swedish. Dordrecht: Reidel.

Engdahl, Elisabet \& Anu Laanemets. 2015. Prepositional passives in Danish, Norwegian and Swedish: A corpus study. Nordic Journal of Linguistics 38(3). 285-337. 
Garbacz, Piotr. 2014. Negation - subject embedded word order. Nordic Atlas of Language Structures (NALS) Journal, 1. 307-321. doi:10.5617/nals.5400.

Gelderen, Elly van. 2009. Where did late merge go? Grammaticalization as feature economy. Studia Linguistica 62(3). 287-300. doi: 10.1111/j.14679582.2008.00150.x.

Hawkins, John A. 2004. Efficiency and complexity in grammars. Oxford: Oxford University Press. doi:10.1093/acprof:oso/9780199252695.001.0001.

Lindstad, Arne Martinus, Anders Nøklestad, Janne Bondi Johannessen \& Øystein Alexander Vangsnes. 2009. The Nordic dialect database: Mapping microsyntactic variation in the Scandinavian languages. In Kristiina Jokinen \& Eckhard Bick (eds.), Proceedings of the 17th Nordic Conference of Computational Linguistics NODALIDA 2009 (NEALT Proceedings Series Volume 4), 283-286. Northern European Association for Language Technology (NEALT). Electronically published at Tartu University Library (Estonia). http:// hdl.handle.net/10062/9206.

Lohndal, Terje. 2007. That-t in Scandinavian and elsewhere: Variation in the position of C. Working Papers in Scandinavian Syntax 79. 47-73.

Lohndal, Terje. 2009. COMP-t effects: variation in the position and features of C*. Studia Linguistica 63:2. 204-232.

Nordgård, Torbjørn. 1985. Word order, binding and the empty category principle. Cand. Philol. thesis, University of Trondheim.

Nordgård, Torbjørn. 1988. Omkring ordstilling i hv-spørsmål i norske dialekter. Skriftserie fra Institutt for fonetikk og lingvistikk, University of Bergen 33, 2637.

Østbø Munch, Christine. 2013. North Germanic negation: A microcomparative perspective. PhD Dissertation, UiT The Arctic University of Norway.

Perlmutter, David M. 1968. Deep and surface structure constraints in syntax. Doctoral dissertation, Massachusetts Institute of Technology. http://hdl.handle. net/1721.1/13003.

Perlmutter, David M. 1971. Deep and surface structure constraints in syntax. New York: Holt, Rinehart and Winston.

Pesetsky, David. 2016. Complementizer-trace effects*. Ms., MIT. https://ling.auf. net/lingbuzz/002385

Schippers, Ankelien. 2017. On the variability of COMP-trace effects: A processing explanation. Paper presented at Comparative Germanic Syntax Workshop 32, Trondheim.

Thráinsson, Höskuldur, Hjalmar P. Petersen, Jógvan í Lon Jacobsen \& Zakaris Svabo Hansen. 2012. Faroese: An overview and reference grammar. $2^{\text {nd }}$ edn. Fróðskapur Faroe University Press \& Linguistic Institute, University of Iceland.

Vangsnes, Øystein A. 2007. Scandinavian dialect syntax (before and after) 2005. Nordlyd 34. 7-24. doi:10.7557/12.86. 
Vangsnes, Øystein A. \& Janne B. Johannessen. 2019. The Nordic research infrastructure for syntactic variation: Possibilities, limitations and achievements. Glossa: A Journal of General Linguistics 4(1). 26. doi:10.5334/gjgl.708.

Vikner, Sten. 1995. Verb movement and expletive subjects in the Germanic languages. Oxford: Oxford University Press.

Westergaard, Marit, Øystein A. Vangsnes \& Terje Lohndal. 2017. Variation and change in Norwegian wh-questions: The role of the complementizer som. Linguistic Variation 17(1). 8-43. 